\title{
Practices, Challenges and Opportunities of Early Childhood Care and Education Program Implementation in Bahir Dar City Administration
}

\author{
Molla Bekalu Mulualem \\ Debre Markos University, Institute of Education and Behavioral Sciences, Department of Teacher Education and \\ Curriculum Studies
}

\begin{abstract}
The major purpose of this research was assessing practices, challenges and opportunities of ECCE program implementation in selected private and government preschools in Bahir Dar city administration. To achieve this purpose, descriptive survey design was employed. From a total of 83 pre-primary schools, 16 schools were selected as a sample of the study using simple random technique. Data was collected from Pre-school teachers/facilitators (62), principals (6) and pre-primary education experts of AREB (1) through questionnaire, interview, observation and document analysis. The quantitative data obtained from questionnaires were analyzed using descriptive (percentage and frequency) and inferential statistics (one sample t-test, independent sample ttest). On the other hand, the qualitative data obtained through interview, open-ended questionnaires, observation and document analysis were analyzed qualitatively in narrative form and used to supplement and/or triangulate the responses given and the results obtain through questionnaires. Accordingly, the results of the study has revealed that the awareness status of both governmental and non-governmental kindergarten teachers/ facilitators on the newly developed Amhara Regional State ECCE strategies and guidelines was found low. The status of physical learning environment governmental schools were found at low level where as nongovernmental preschools was found at high level. Moreover, the status on the use of child-centered methods of teaching and assessment practices for children in both governmental and non-governmental preschools was found at high level. Furthermore, the status of parents' involvement on their children education the governmental preschools were found at low level where as non-governmental preschools was found at high level. Statistical significant difference was not observed between governmental and nongovernmental preschools in awareness level of ECCE guidelines and the application of child-centered teaching methods but statistical significant difference was found in on conduciveness of physical learning environment, use of assessment practices and parents involvement. Lack of early childhood education professionals, low stakeholders participation and support, lack of standard curriculum and lack of adequate budget and monitoring system of the program were the challenges identified in the study. To this end, the recommendation are refreshment trainings, workshops, and seminars on the issue of ECCE need be prepared jointly by all relevant stakeholders so that everyone can get awareness and take the responsibility under common understanding. Continuous in service trainings should be provided for preschool teachers who are already in the service so that the quality of their teaching would be improved and provide continuous training and quality improvement efforts to all preschool teachers and program. Keywords: Practices, Challenges and Opportunities
\end{abstract}

DOI: $10.7176 / \mathrm{JEP} / 10-1-03$

\subsection{Background of the Study}

The experiences of children in their early years, i.e. before they enter formal primary schools are very important in affecting their long-term cognitive and social development. Children's development, in turn, affects not only their personal well-being but also their capacity to contribute to the well being of society in general. Childhood stage, the period between birth and eight years of life is the foundation for inculcation of social values, personal habits which are known to last a lifetime (Osakwe, 2009). Early childhood is a critical period for developing the brain to be able to handle information, express emotions normally and be proficient in language (UNICEF, 2012).

Early childhood is a critical time in life when young children learn skills and develop abilities that set the stage for future development. Social-emotional development is at the foundation of healthy growth and learning in early childhood. Children develop competencies in these areas through observation, interactions with peers and adults, and learning experiences that promote children to practice new skills for continued growth. The social emotional domain includes abilities and skills in social and emotional competency. Both are critical areas of development that enable children to interact positively with others, and attend to academic tasks that help prepare them for future academic success (Ashiabi, 2007).

Kindergarten education is the pre-school preparatory education for children and can take up to two or three years. In this program, children between the ages of four to six years are offered fun-like education that would enable them to express their feelings, to appreciate beauty, and to learn to distinguish and form letters and 
numbers. Play is a significant aspect of a kindergarten employing games, songs, specially chosen work materials, and stories to address the needs of small children. It is aimed at growing children in a free atmosphere away from home. Kindergartens provide early childhood education programs for children in the year or two before school during typical school hours. Preschool programs aim to provide early developmental and educational activities to foster children's social and cognitive maturation, and to help prepare them for school. It requires high investment and trained manpower (MoE, 2002).

Improving the quality of education is always an issue everywhere and any time. The only difference from country to country is the target intended to be achieved i.e. the purpose. At present the government of the FDRE has taken multi pronged measures to improve quality of education in the country. Preschool education has become one of the potential inputs to the overall improvement of quality of education and reduction of drop out and repetition rates in later stages of schooling and it is believed to lead to higher enrollments of students (MoE, 2010). Provision of a comprehensive early intervention is one of the effective means to end educational disparities in societies and children who received quality early intervention stay in school longer, are likely to finish high school, less likely to repeat grades and placed in special education (Dedeoglu \& Alat, 2012). Moreover, Ige (2011:166), conclude that:

Early childhood is an important stage in the life of an individual. Education being provided at this age serves as the foundation on which future education rests. At this stage, proper attention needs to be given to a child since a house that is built on rock withstands the test of time while the one built on sand or shaky foundation will collapse like house of cards.

If early years are not supported by stimulating and enriching physical and psycho-social environment, the chances of a child's brain development to full potential is low(UNICEF,2012). At this stage, a child's health, intellect, personality, character, emotional stability among others, is molded. A child development is thus a continuous and cumulative process so that what proceeds influences what follows. What follows logically is the crucial importance of investing in early years to ensure an enabling environment for every child, and sound foundation for life which is not only the right of every child but which will impact in the long term, the quality of human capital available to a country. As a matter of fact, early child hood education and care has received an increasing amount of attention in the last two decades (UNESCO, 2012).

Early childhood education and care simply refers to a range of processes and mechanisms that sustain and support development during early years of life: it encompasses education, physical, social and emotional care, intellectual stimulation, health care and nutrition (UNICEF, 2012). It also includes the support a family and community need to promote children's healthy development. Early childhood education and care is one of the most important phases in a child's life. There is an enormous amount of research proving that when children attend high quality early childhood programs, they have better chances of succeeding in school, going to college and getting a higher paying job(Osakwe, 2009). Quality early childhood programs provide children with the tools they need to learn social, behavioral and learning skills at their own pace, in terms they can understand.

In its comprehensive education policy, Ethiopia recognizes the importance of kindergarten education by putting its goal for all round development of the child in preparation for formal schooling (MoE, 1994) though insignificant attention was given in practice. In order to improve ECCE Ethiopia developed National Policy Framework for ECCE which shows the commitment of the country toward ECCE implementation and it is one step ahead in giving due attention to the crucial issue. Guidelines for Preschools (4 to $6+$ year) give clear instructions regarding the physical space of the preschools, cleanliness, sanitation facilities and the recommended minimum number of children for one teacher and one assistant. The recommendations are also given on learning materials, (visual, and rich in colour), outdoor play equipment, preschool curriculum and scheduling of preschool activities. The minimal qualifications for teachers and assistant teachers are given, as well as the guidance for pedagogically sound teaching and learning methodology, to focus on teacher child interaction and active learning. The parents are guided to have regular contacts with teachers and teachers are guided to carry out holistic, continuous assessment (MoE, 2010). When we see early childhood care and education practice in Ethiopia, teachers are not well trained for pre-school teaching: they are not working in collaboration with families, and other professionals (MOE, 2009). Furthermore, the existing urban-based modern pre-primary schools are limited for children of age 4 to 6 and are not also inclusive for children with special needs (Demeke, 2007).

According to the Sector Development Program IV (ESDP IV):

Participating in ECCE is the right of the child and it has been considered as bedrock of EFA and the first step in meeting all the other EFA goals. This in turn contributes to the overarching Millennium Development Goal of reducing poverty. Affordable and reliable early childhood education provides essential support for working parents, particularly mothers. Besides, ECCE has positive effects on female labor force participation and schooling of older siblings. 
The strategic operational plan and guide line for Early Child Care and Education in Ethiopia (FDRE: MOE, MOH and MOWA 2010) also pointed out that; children in Ethiopia starting at the age of 4-6 year olds to participate in either in the Child to Child Initiative programme by the help of grade 5th and 6th older brothers or sisters (the young facilitators) play with their younger siblings and neighbour children. In this program the younger facilitator gets training once a week, at school, by his or her Home room teacher and then at least once a week the young facilitator will play with three to five preschool children in the community (relatives, neighbors or friends), close to the children's home; or enrolling in the ' $\mathrm{O}$ ' Class programme which are supposed to be opened one ' $\mathrm{O}$ ' Class in every primary school found in Ethiopian governmental schools. Through these the preschool child gets ready for school and playing becomes learning as the benefiting child gets to know how for instance, to count or to differentiate colors and identify letters.

Even though the works of many scholars such as those cited above indicate that ECCE has an enormous effect for the overall development of the child the government of Ethiopia did not give high attention like other levels of education for along period of time. However, taking to consideration the low level of emphasis for ECCE and the comments given by many international organizations like UNICEF and UNESCO the government of Ethiopia start to give attention for ECCE by developing a separate National ECCE framework in 2010. Based on the National framework, the Amhara National Regional State Education Bereau(ANRSEB) has developed regional guidelines and strategies to facilitate the implementation of ECCE program in the region.

Thus, the focus of this study is to assess the current practices and challenges of ECCE program implementation in Bahir Dar city administration.

\subsection{Statement of the Problem}

Early childhood care and education (ECCE) provision is becoming a growing priority, and has received increased policy attention, in many countries during the past years. Equitable access to quality early childhood education is also increasing viewed by policy makers as a way of strengthening the foundations of lifelong learning for all children and supporting the educational and social needs of families (UNESCO, 2012). Though the contribution of ECCE towards broader social, economic and education goals is being recognized, the sector remains under-developed in a number of countries due in part to a lack of investments, as well as the diversity of bodies and actors involved in its organization and provision that may not be well coordinated and/or regulated (Education International,2010).

The focus of Ethiopia's education policy to date has been on improving primary schools in terms of both access and quality. However, preschool education has been a much lower government priority. The absolute number of trained teachers remains small. The government's stance, namely that private, public, religious and other organizations should be tasked with providing preschool education, was questioned by academics, NGOs and even branches of the government in Ethiopia (MoE, 2002).

In Ethiopia children constitute a large section of the population. Over $45 \%$ of the current populations are children below fifteen years age. However, like in other developing countries, children's access to resources is limited; opportunities for education, health, adequate nutrition, recreation, etc are highly limited; and a considerable part of the child population is exposed to different forms of exploitation and abuse, hindering the full realization of their potentialities (MoE, 2010).

An assessment study conducted in 2007, cited in National Policy Frame Work Early Child Care and Education in Ethiopia (2010:15), identified that the major challenges are high payment that is requested to attend the preschool education; lack of proper training of preschool teachers, standard curriculum and guidelines; culturally relevant story books; quasi non-existence of alternative care and education services for the majority of the children population in the rural areas; access to early children from low socio economic backgrounds, awareness about the value of type of care and education for young children; low salary for teachers causing high staff turnover; lack of early child hood education professionals misconception about teaching children because they are children " and the use of foreign languages (mainly English) as a medium of instruction

The MoE educational statistics annual abstract of (2010/11) reported that preschool education is one of the most neglected areas in Ethiopia. Out of the estimated 7.31 million children of the appropriate age group (age 46) only 5.2\% (Boys 197,671 girls 185,070 Total 382,741) of the country; have access to pre-primary education in 3481 and 195 kindergartens respectively....gross enrolment rate was comparatively small in all regions.... Cognizant of this fact, the government of Ethiopia has promulgated a national ECCE policy framework in 2010. The policy envisions to ensure all children the right to a healthy start in life, be nurtured in a safe,caring and stimulating environment and develop to their fullest potential. The policy document appreciates important concepts in early childhood development such as developmentally appropriate ECCE program for the holistic development of children. The policy document as well underlines the importance of active involvement of parents in the overall undertakings of ECCE programs (MoE, 2010).

In its comprehensive education policy, Ethiopia recognizes the importance of kindergarten education by putting its goal for all round development of the child in preparation for formal schooling (MoE, 1994:14) 
though insignificant attention was given in practice. As indicated earlier, Ethiopia developed separate National Policy Framework for ECCE which shows the commitment of the country toward ECCE implementation and it is one step ahead in giving due attention to the crucial issue.

When we see early childhood care and education practice in Ethiopia, teachers are not well trained for preschool teaching: they are not working in collaboration with families, and other professionals (MOE, 2009). Furthermore, the existing urban-based modern pre-primary schools are limited for children of age 4 to 6 and are not also inclusive for children with special needs (Demeke, 2007).

In line with the above national framework, the Amhara National Regional State Education Bereau has also launched a regional ECCE strategy and guide line to be implemented throughout the region (AREB, 2011). In this regional document the major stakeholders and actors of the program and their specific duties and responsibilities are explicitly outlined. Based on this regional strategy and guideline an effort has been made to provide ECCE program in Bahir Dar city administration.

Though an encouraging effort to make ECCE program effective has been made in the city, there is wide spread dissatisfaction and uncertainty on the success of the program. Major stakeholders, especially the city education office, women and children affairs office and the implementing primary schools have been always debating on the root causes for the programs ineffectiveness. Besides, as of the knowledge of the researcher, no scientific research has been conducted on the practices, challenges and opportunities of ECCE in the study area. Therefore, these are the grounds to think over and initiate this research undertaking.

In line with that, the study will attempt to answer the following research questions.

1. What is the status of ECCE program implementation in Bahir Dar City Administration?

2. Is there statistical significant difference between government and nongovernmental ECCE program implementation concerning awareness of ECCE strategies and guidelines, learning environment, teaching methods, assessment and parents' involvement practices?

3. What are the major challenges that affect the smooth implementation of the ECCE program in Bahir Dar City Administration?

4. What are the opportunities that facilitate the implementation of ECCE in Bahir Dar City Administration?

\subsection{Objectives of the Study}

General objectives

The general objective of this research is to assess the current practices and challenges of ECCE in Bahir Dar City Administration

Besides, this study has the following specific objectives:

- Describe the current status of ECCE program implementation in Bahir Dar City Administration in terms of ECCE awareness, learning environment, methods, assessment practices and parents' involvement.

- Determine the significant difference between government and non-governmental ECCE program implementation concerning awareness of ECCE guidelines, learning environment, developmentally appropriate teaching methods, developmentally appropriate assessment practices and parents' involvement?

- Identify the major challenges and opportunities that hinder/facilitate the smooth implementation of ECCE program in Bahir Dar City Administration.

\subsection{Delimitation of the study}

Geographically, this study was delimited to governmental and private ECCE program provision kindergartens/primary schools found in Bahir Dar city administration. The study is also conceptually delimit to the investigation of practices and challenges of ECCE in line with the framework of developed by MoE and the guidelines enacted by the Amhara Region Education Bureau.

\subsection{Significance of the Study}

This research is expected to be important for various stakeholders involved in the program.

- The study findings could serve as invaluable input for Bahir Dar city education office for their future decision makings.

- $\quad$ To suggest some possible measures to government bodies (at city level and at the regional level) so as to improve the quality of ECCE program implementation both in government and private pre-primary schools.

- The study is also expected to benefit both private and governmental kindergarten institutions to have indepth understanding in the implementation process of the ECCE program, so that; they will use findings of the study for better implementation of the program in the future.

- Finally, this study could serve as springboard for those individuals and institutions that are interested to 
carry out further research on the issue at hand.

\subsection{Operational Definition of Terms}

Early Childhood - The period of a young child between the ages of 4 to 6 years old.

Early Childhood Care and Education (ECCE): ECCE refers to a comprehensive approach to policies and programs for children from prenatal to seven years of age, (MoE, 2010a). But ECCE in this research refers to all educational services provided for children age 4 to 6 both on governmental and non-governmental preschools.

Kindergarten - a school that focuses on all-round development of the child (age 4-6) in preparation for formal schooling. (MoE 1994:14)

Facilitators-a professional (a teacher) assigned to manage the instructional process of ECCE in the classroom.

Non-governmental kindergartens- include all institutions that provide ECCE program out of the government (private owned, missionaries, church)

\subsection{Research Methodology}

\subsubsection{Research Design}

The major purpose of this research is assessing practices, challenges and opportunities of ECCE in selected private and government pre schools in Bahir Dar city administration. To achieve this purpose, descriptive survey design was employed in this study. The underlying reason for employing this type of study was its appropriateness to describe present conditions and gather a large variety of data related to the problem (Best \& Kahn, 1999).

\subsubsection{Sources of Data}

The sources of primary data were preprimary school teachers/facilitators, principals and experts in the city administration. Books, Journals, and legal documents were used as sources of data.

\subsubsection{Population, Samples and Sampling Techniques}

In Bahir Dar city administration there are 5 governmental kindergartens and 35 government primary schools which provide ECCE program at O-class level) and 43 private kindergartens(pre-primary schools). The selection procedures were indicated as follows:

\section{Schools}

The study site (Bahir Dar city administration) is selected purposely due to the easy access of the researcher. In the city there are 5 government kindergartens, 35 government primary schools which provide early childhood education in the $\mathrm{O}$-class level and 43 private kindergartens. Of these total number of government kindergartens and primary schools 4 government kindergartens, 5 government primary schools which provide O-class were selected as the sample of the study using simple random sampling techniques respectively and also 7 private kindergartens were selected as the sample of the study using simple random sampling technique. Thus, a total of (16), 9 government and 7 private kindergartens were selected as the sample of this study.

\section{Kindergarten Teachers/Facilitators, Principals and Experts}

All teachers of targeted government kindergartens and assigned facilitators/teachers in primary schools which offered O-class level were selected as data source of the study using comprehensive sampling technique. On the other hand, from each sample of private kindergartens under the study about $50 \%$ teachers were selected using simple random technique. For observation and interview along with government and private kindergartens three schools and three principals among each group were selected randomly to make it manageable in such a way that it can represent the targeted population. Moreover, pre-primary education experts from the city were purposely included to participate in providing information through interview since they are the ones that have got strong attachment to the programme implementation due to their responsibility.

Thus, 32 government kindergarten teachers/facilitators, 30 private kindergarten teachers, 6 principals and 1 pre-primary education expert were selected as subjects of the study.

\subsubsection{Data Gathering Instruments}

Questionnaire, interview, observation and relevant documents were used as data collection tools.

Questionnaire

Questionnaires were designed as both close- ended and open ended items and distributed to both government and private kindergarten teachers/facilitators. The questionnaires were developed based on the review of related literatures and were commented on by professional colleagues for its relevance, completeness, and clarity, then, it was translated into Amharic language by the researcher and by one MA language student in Bahir Dar University and also commented by my two colleagues (Amharic language teachers in Debre Markos University) for the appropriateness of the translation.

\section{Interview}

Interview was conducted to gather data from pre-primary education expert and principals concerning the practices, challenges and opportunities of ECCE program implementation. Semi-structured questions were used to guide the interview. After explaining the purpose of the interview for the interviewees and getting their 
consent, the researcher has conducted the interview and recorded the information by taking notes on the main themes of the discussion. The interview was conducted in Amharic language.

\section{Observation}

Check list were prepared and six randomly selected (3 government and 3 private owned kindergartens) were observed by the researcher himself to collect and organize relevant data on key inputs and overall indoor/outdoor environment of kindergartens including their documentation along with their entire contents of about the overall current status on the ground by using checklist.

\section{Document Analysis}

Document analysis was the other essential data collecting tool. Various documents including preschool performance reports, guidelines of the MoE and ANRSEB, assessment techniques were explored in the process of the study. It is believed that the data obtained in this method was used to validate and substantiate the information gathered by the questionnaire and interview.

\subsubsection{Method of Data Analysis}

In this study, both quantitative and qualitative data analysis techniques were employed. Thus, the quantitative data were analyzed by employing descriptive statistics(frequency and percentage) were used to analyze various characteristics of the participants in the study like sex, work experience, and educational qualification as it helps to determine the relative standing of the respondents. Furthermore, mean and one-sample t-test was used to see the status of ECCE program implementation and independent sample t-test was used to see the existence of statistical significant differences between government and non-government ECCE program implementation. In using the one sample t-test and independent sample t-test SPSS of the 20 version was employed. The 0.05 alpha level was accepted as a criterion of statistical significance for all the statistical procedure performed. On the other hand, the qualitative data obtained through interview, open-ended questionnaires, observation and document analysis were analyzed qualitatively and used to supplement and/or triangulate the responses given and the results obtain through questionnaires.

\section{Major Findings}

\section{Characteristics of the Respondents}

Totally 62 copies of questionnaires for teachers/facilitators were distributed. From the distributed questionnaires $62(100 \%)$ of the teachers/facilitators were filled in and returned. It was this figure that would be considered as total respondents in the analysis part of the study. On top of this, to raise the quality of the data and information interview was conducted with 6 school principals and 1 ECCE Coordinator.

\section{Status of ECCE in Bahir Dar City Administration}

Describing the status of ECCE program implementation in Bahir Dar city administration was one of the objectives of this study. In line with this objective, an attempt was made to gather both quantitative and qualitative data. Hence, this part indicates findings vis-à-vis the status of ECCE programs in Bahir Dar city administration.

Table 1: Descriptive statistics for the Status of ECCE program

\begin{tabular}{|l|l|l|l|l|l|}
\hline & School type & $\mathrm{N}$ & Mean & Std. Deviation & $\begin{array}{l}\text { Std.Error } \\
\text { Mean }\end{array}$ \\
\hline \multirow{2}{*}{$\begin{array}{l}\text { Awareness level of ECCE } \\
\text { strategies \&guidelines }\end{array}$} & Government & 32 & 2.1927 & .62089 & .10976 \\
& Non-government & 30 & 2.2056 & .32069 & .05855 \\
& Total & 62 & 2.1989 & .49482 & .06284 \\
\hline \multirow{4}{*}{ Learning Environment } & Government & 32 & 2.1719 & .37609 & .06648 \\
& Non-government & 30 & 3.5167 & .31193 & .05695 \\
& Total & 62 & 2.8226 & .75973 & .09649 \\
\hline \multirow{4}{*}{ Child-centered Methods } & Government & 32 & 3.1594 & .46826 & .08278 \\
& Non-government & 30 & 3.3367 & .25255 & .04611 \\
& Total & 62 & 3.2452 & .38695 & .04914 \\
\hline \multirow{4}{*}{ Assessment Practices } & Government & 32 & 3.0199 & .26803 & .04738 \\
& Non-government & 30 & 3.4485 & .39078 & .07135 \\
\hline \multirow{3}{*}{ Parents Involvement } & Total & 62 & 3.2273 & .39464 & .05012 \\
& Government & 32 & 2.3062 & .59021 & .10434 \\
& Non-government & 30 & 3.3600 & .46801 & .08545 \\
& Total & 62 & 2.8161 & .75034 & .09529 \\
\hline
\end{tabular}

Table 1 above indicates the status of ECCE program implementation in Bahir Dar city administration both in governmental and non-governmental kindergartens. It would be interesting to see the distribution of mean values with regard to school types. A mean score of below three is taken as being low status of ECCE program implementation. A mean score of three is taken as average/ medium status and a mean score of above three is taken as high status of ECCE program implementation. Thus, as can be seen from this table the awareness level 
of both governmental and non-governmental kindergarten teachers/ facilitators on the newly developed Amhara Regional State ECCE strategies and guidelines was found low ( mean values of $\mathrm{M}=2.19$ and $\mathrm{M}=2.21$ respectively).

With regard to the status of physical learning environment (indoors and outdoors facilities) to implement ECCE program effectively the status of governmental schools were found at low level where as the status of non-governmental kindergartens were found at high level (mean values of $\mathrm{M}=2.17$ and $\mathrm{M}=3.52$ respectively). This means nongovernmental preschools are significantly better in their indoors and outdoors resource provision than governmental preschools. The result is also supported with the finding obtained from observation. Because during observation it was approved that the sample governmental preschools have no adequate outdoor playing materials but all nongovernmental preschools do have.

In relation to the status on the use of child-centered methods of teaching and assessment practices for children in both governmental and non-governmental kindergartens were found at high level (mean values of $\mathrm{M}=3.16$ and $\mathrm{M}=3.34$ respectively) and (mean values of $\mathrm{M}=3.02$ and $\mathrm{M}=3.45$ respectively). The result indicates that governmental and nongovernmental preschools are almost at the same level of practice in their childcentered methods and assessment.

Regarding to the status of parents/guardians involvement on their children education the status of governmental schools were found at low level where as the status of non-governmental kindergartens were found at high level ( mean values of $\mathrm{M}=2.31$ and $\mathrm{M}=3.36$ respectively).

To determine the status level of government and non-government kindergartens about ECCE program implementation( awareness of ECCE guidelines, conduciveness of the physical learning environment, use of child centered teaching methods, assessment practices and the involvement of parents/guardians on their children education) the observed means were tested for their differences from the expected mean (3.00) in a one-sample ttest. The results of one-sample t-test have been presented in the following table.

Table 2: One Sample T-test Results

\begin{tabular}{|c|c|c|c|c|c|c|}
\hline \multirow{3}{*}{ Variables } & \multicolumn{6}{|c|}{ Test Value $=3$} \\
\hline & \multirow[t]{2}{*}{$\mathrm{t}$} & \multirow[t]{2}{*}{ Df } & \multirow[t]{2}{*}{$\begin{array}{l}\text { Sig.(2- } \\
\text { tailed) }\end{array}$} & \multirow[t]{2}{*}{$\begin{array}{l}\text { Mean } \\
\text { Difference }\end{array}$} & \multicolumn{2}{|c|}{$\begin{array}{l}95 \% \text { Confidence Interval of the } \\
\text { Difference }\end{array}$} \\
\hline & & & & & Lower & Upper \\
\hline Awareness status & - & 61 & .000 & -.80108 & -.9267 & -.6754 \\
\hline Learning Environment & -1.839 & 61 & .071 & -.17742 & -.3704 & .0155 \\
\hline $\begin{array}{l}\text { Child centered } \\
\text { Methods }\end{array}$ & 4.989 & 61 & .000 & .24516 & .1469 & .3434 \\
\hline Assessment practices & 4.535 & 61 & .000 & .22727 & .1271 & .3275 \\
\hline Parents Involvement & -1.930 & 61 & .058 & -.18387 & -.3744 & .0067 \\
\hline
\end{tabular}

The results in Table 2 indicated that there exist significant mean differences between the expected mean and observed mean in awareness of ECCE guidelines, use of child- centered teaching methods and assessment practices at $p<0.05$ level of significance where as there is no significant mean differences between the expected mean and observed mean in learning environment and parents involvement at $\mathrm{p}<0.05$ level of significance.

Table 3: Independent Sample t-test for Difference in Governmental and Non-government kindergartens in different variables

\begin{tabular}{|l|l|l|l|l|c|c|c|}
\hline \multicolumn{1}{|c|}{ Variables } & School type & $\mathrm{N}$ & Mean & Std. Deviation & $\mathrm{df}$ & $\mathrm{t}$ & Sig.(2-tailed) \\
\hline \multirow{2}{*}{ Awareness status } & Government & 32 & 2.1927 & .62089 & & & \\
& Non-government & 30 & 2.2056 & .32069 & 60 & -1.01 & .920 \\
\hline \multirow{2}{*}{ Learning environment } & Government & 32 & 2.1719 & .37609 & & & \\
& Non-government & 30 & 3.5167 & .31193 & 60 & -15.269 & .000 \\
\hline \multirow{2}{*}{ Child-centered methods } & Government & 32 & 3.1594 & .46826 & 60 & & \\
& Non-government & 30 & 3.3367 & .25255 & & -1.838 & .071 \\
\hline \multirow{2}{*}{ Assessment Practices } & Government & 32 & 3.0199 & .26803 & 60 & & \\
& Non-government & 30 & 3.4485 & .39078 & & -5.064 & .000 \\
\hline \multirow{2}{*}{ Parents Involvement } & Government & 32 & 2.3062 & .59021 & & & \\
& Non-government & 30 & 3.3600 & .46801 & 60 & -7.756 & .000 \\
\hline
\end{tabular}

Table 3 depicts that there was a statistically significant differences between government and nongovernment kindergartens about ECCE program implementation on conduciveness of physical learning environment, use of developmentally appropriate assessment practices and parents/guardians involvement that the t-test $(\mathrm{T}=-15.269, \mathrm{p}<0.05, \mathrm{~T}=-5.064, \mathrm{p}<0.05, \mathrm{~T}=-7.756, \mathrm{p}<0.05$ respectively) where as there is no significant mean differences between government and non-government ECCE program implementation among the 
respondents in awareness status level of ECCE guidelines and the application of child-centered teaching methods at $\mathrm{p}<0.05$ level of significance.

Challenges Encountered in the Implementation of ECCE

The results found through open-ended questionnaires and interview with school principals and city education expert showed that there are a number of challenges encountered during the implementation of ECCE program in the city. The major challenges which are faced in the practices of ECCE program as raised by the respondents are related to lack of early childhood education professionals, absence and inadequacy of official curricula documents low, stakeholders participation and support to the program, challenges related to resources, challenges related to teaching learning process and lack of appropriate budget and monitoring system of the program.

In the interview, the city administration education office ECCE coordinator had said that the following to say.

You know the quality and effective implementation of ECCE program is largely determined by the availability of ECCE resources and the quality of ECCE teachers. Though the basic resources that should be fulfilled in the implementation of the program are well articulated in different government documents, in reality almost none of them are sufficiently available in our schools especially in governmental pre-primary schools.

In the same regard, one of the governmental school principal replied as follows.

Lack of basic resources is one of the serious challenges that hinder the effective implementation of

ECCE program. The status of classrooms and play materials are quite unacceptable in our schools.

In relation to resources and kindergarten teachers, one of the interviewee's private school principal said that:

In our school there are different factors that hinder the implementation of ECCE program such as scarcity of qualified kindergarten teachers on areas of ECCE, scarcity of some basic materials and lack of adequate support and monitoring from the government bodies.

The qualitative data obtained from through open ended questionnaire from teachers was also quite similar with the qualitative data obtained from the above interviewees. The major challenges mentioned by especially the government kindergarten teachers were high number of children in a classroom, no or inefficient teaching aids, absence of adequate playground, lack of sufficient playing equipment, no or inappropriate sleeping area, shortage of water, not adequate toilet and cleanliness. Others said, there should be more trained caregivers who can help with feeding and cleaning the children. In relation to teachers training, most of them said that they need to get in-service training just like any other teacher. They also mentioned, low salary and motivation for such a demanding job.

In all ECCE's, the observation checklist showed that most of the equipment, teaching learning materials and playing items are not up to the standard. In few schools, even though the equipments are there they are not functioning. In others, the equipment is not enough for all the kids to play and they have to wait for they turn. Overall, there is shortage, properly working and enough materials and equipment suitable for all the children..

\section{Opportunities for the Implementation of ECCE}

Clear Policy Direction

As already indicated in the background and literature review part of this study, the Ethiopian government has launched a national policy framework for ECCE implementation and the Amhara National Regional Bureau also formulated regional guidelines and strategies based on the National framework. The policy documents explain too many specific issues in relation to the different issues of ECCE. Therefore, almost all respondents and interviewees acknowledge this as one important opportunity for the implementation of the program all over the schools.

\section{International Trend on ECCE}

ECCE has been one of the concerns of many developing and developed countries and international organizations. Due to this, it has now become an international agenda. For instance, ECCE was one of the first of the six goals of the Education for All (EFA) initiative declared at Dakar in 2000. Therefore, many research participants indicated this international initiative as one opportunity for ECCE implementation in Ethiopia.

\section{Possibility of International Support and Involvement of different Stakeholders}

ECCE has become the major concern of many national and international organizations. For instance, international organizations such as UNICEF and UNESCO have been investing much for the realization of ECCE principles in different parts of the world. They allocate a huge amount of money to support national ECCE efforts. Similarly, different national stakeholders such as private investors, religious institutions, and communities have been involved in the implementation of the program. Recognizing this, the research participants, particularly the city administration ECCE coordinator mentioned this as one valuable opportunity for the better implementation of ECCE in the Ethiopian context.

Positive Attitude towards ECCE Program

Another important theme constructed in analyzing qualitative data concerning opportunities was the prevalence 
of a positive attitude towards the benefits of ECCE. Many respondents indicated that unlike many educational initiatives introduced by the government, the ECCE program was welcomed almost by all major stakeholders.

\section{Conclusion}

Based on the major findings presented above the following conclusions were made.

- Concerning the status of ECCE program regarding to awareness level of ECCE strategies and guidelines, learning environment, child-centred teaching methods, assessment and parents' involvement practices in governmental and non-governmental (private) schools, it was explored that both governmental and nongovernmental school facilitators/teachers were at lower status on awareness of the regional guidelines and strategies. Regarding the physical learning environment and parental involvement the governmental schools were found at low level where as the private schools were found at adequate level in this matter.

- Both government and private kindergarten teachers employed child centred teaching methods and assessment strategies in the classroom.

- The participation of parents in private pre primary schools was found better than government kindergarten schools.

- Lack of early childhood education professionals, low stakeholders participation and support, no standard curriculum, lack of adequate budget and monitoring system of the program were some of the major challenges that hindered the implementation of the program.

- Clear policy direction, international trend on ECCE, possibility of international support and involvement of different stakeholders and positive attitude towards ECCE program were some of the major opportunities of ECCE program.

\section{Recommendations}

- It is advisable to the concerned governmental bodies (MOE, REB, WEOs, and Schools) to work closely with other concerned stake holders to give priority for preschool education. Because this level is the foundation of all the other levels, where children start an important part of their personality development.

- Refreshment trainings, workshops, and seminars on the issue of ECCE need be prepared jointly by all relevant stakeholders so that everyone can get awareness and take the responsibility under common understanding. It is also advisable to institutionalize the coordination efforts through establishing a sort of sectoral/institutional network at all levels.

- It is advisable to employ teaching methods, such as brainstorming, play based learning, cooperative learning, storytelling and integrated rhythm, music and dance method effectively to implement ECCE and attract the attention of children.

- $\quad$ Empowering parents' Involvement in their children's education; preparation and effective utilization of locally produced teaching aids, employing effective teaching methods such as, teaching children through integrating rhythm, music and dance, teaching children through play based learning, teaching children through storytelling and employment of cooperative teaching methods should be shared for both government and private kindergarten schools.

- The organization of classroom and outdoor spaces, materials and equipment, play an important part in helping children to acquire the skills and competencies associated with preschool provision. Therefore, the kindergartens need to provide age appropriate and well equipped materials to facilitate the children need.

- Appropriate and adequate orientation should be given for both governmental and nongovernmental teachers/principals about ECCE framework, strategies and guidelines.

\section{References}

Amelework, H. (2007). Evaluation of kindergarten curriculum implementation in east Showa Zone. Unpublished MA Thesis of the AAU.

Ashiabi, G. S. (2007). Play in the preschool classroom: Its socioemotional significance and the teacher's role in play. Early Childhood Education Journal, 35(2).

Best, J. W. \&Kahan, J. V. (1998). Research in Education (8thed.). New York: Allyn\& Bacon Boren,

Bowman, B. T. (2003). Early childhood education and care in the USA. In D. Cryer \& R. M. Clifford (Eds.), Family engagement and support (pp. 1 19-13 6). Baltimore, MD: Paul H. Brookes Publishing Co. Sociology of Encyclopedia: Newyork: Routlege Falmer.

Bredekamp, S. \& Copple, C. (1997). Developmentally appropriate practice in early childhood programs (Rev.ed.). Washington, DC: National Association for the Education of Young Children.

Chowdhury, A. \& Choudhury, R. (2002).Pre-school Children: Development, Care and Education.New Delhi: 
New Age International Publisher.

Clark, C. \& Peterson, P. (1986). "Teachers' thought processes". In M. C. Wittrock (ed.) Handbook on research in teaching. New York: Macmillan Publishing Co.

Cresswell, J. W. (2009). Research Design: Qualitative, Quantitative, and Mixed Methods Approaches. Thousand Oaks: SAGE

Daniel, G. (2010). The Practice and Problems of Early Childhood Education: the case of Yekatit-12 Kindergarten. Unpublished BA Thesis of the AAU.

Demeke Gessesse.(2007)."Historical and Philosophical Foundations of Early Childhood Education in Ethiopia”. Proceeding of 7 th National Conference, Ethiopia Psychologists

Global Association of Childhood Education International (1986).Literacy Development and pre-first grade: A joint statement of concerns about present practices in pre-first reading instruction and recommendations for improvement. Childhood Education, 63,110-111.

Haile, G. (2010). The Current Practice of Pre-school Education in some selected Weredas of North Western Zone of Tigray. Unpublished MA Thesis of the AAU.

Harvey, G., (2005).The early childhood foundation for lifelong learning. San Francisco: Longman.

Lambert, R., \& Hazel, M. (1960). Early Childhood Education. Boston: Allyn and Bacon.

Ministry of Education (2002). Education Sector Development Program II 2002-5. Addis Ababa: Ministry of Education

Ministry of Education.(2010). Education Sector Development Program IV 2010/20112014/2015. Addis Ababa: Ministry of Education

MoE (1994). Education and Training Policy. Addis Ababa: Berhanena selam Printing Enterprise.

MoE (2002). Education and Training policy and Its Implementation. Addis Ababa: MoE.

MoE (2011).Education statistics annual abstract 2003E.C (2010/2011G.C).Addis Ababa, Ethiopia: Ministry of education

MoE (2013) Education Statistics Annual Abstract 20011/2. Addis Ababa: Government of Ethiopia.

MoE(2009). Guide Lines for standard of Kindergarten and First Cycle Education program. Addis Ababa: MoE.

MoE(2010).National Policy Framework for Early Childhood Care and Education in Ethiopa. Ultimate printing Press; Addis Ababa

Morrison, G. S. (2011).Fundamentals of Early Childhood education (6thed.). New Jersey: Pearson.

NACECE .(2000). Early Childhood Education: A manual for Pre-school teachers and the community. Nairobi: East African Educational Publishers. Retrieved from http://google.com.et/books?id=1tzBQdEnxKkC.

National Association for the Education of Young Children [NAECY] (1997). Developmentally appropriate practice in early childhood programs serving children from birth through age 8. A position statement of NAEYC. Washington, DC: NAECY, pp1-22. Retrieved June 14, 2017

Ojala, M. (1989). Early Childhood Training, Care and Education in Finland. In: P.P. Olmsted

Osakwe,R.N. (2009). "The Effect of Early Childhood Education Experience on the Academic Performances of Primary School Children”. Stud Home Comm Sci,3(2):143-147.

Powell, D. (1989). Families and early childhood programs. Washington, DC: National Association for the Education of Young Children.

Rusher, A.S.,McGrevin, C.Z.,\& Lambiotte,J.G.(1992).Beliefs systems of Early Childhood Teachers and Their Principals Regarding Early Childhood Education. Early Childhood Research Quarterly,7,277-296.

Stegeman, A. \& Wills, J. (1953). Living in the Kindergarten. Chicago: Follet Publishing Company.

Tassoni, P. (1998). Child Care and Education. London: A Division of Reed Educational and Professional Publishing.

Tirussew T. (2007). Child Rights, Childhood Education and the use of Mother tongue Language in schools. In: T. Belay \& M. Abebaw (Eds.) Proceedings of the 7th National conference of the Ethiopian Psychologists Association.

Tirussew, T.(2005). Disability in Ethiopia: Issues, Insights and Implications. Addis Ababa: AAU Printing Press.

UNESCO (2006) "EFA Global Monitoring Report 2007: Strong foundations - Early childhood Care and education." Oxford and Paris, Oxford University Press and UNESCO.

UNESCO(2012). Early Childhood Care and Education. UNESCO Publishing, Paris

UNESCO. (2005). Early childhood care and education in Ethiopia. EFA global monitoring report. Paris, France: Author.

UNESCO-IICBA (2010). County case study on ECCE in selected Sub-Saharan African countries 2007/2008: Some key teacher issues \& policy recommendations. A summary report. Addis Ababa, Ethiopia: UNESCOIICBA.Retrieved February 7/2017,

UNICEF( 2012).Early Childhood Education and Care. UNICEF Publishing;Bangkob. 